
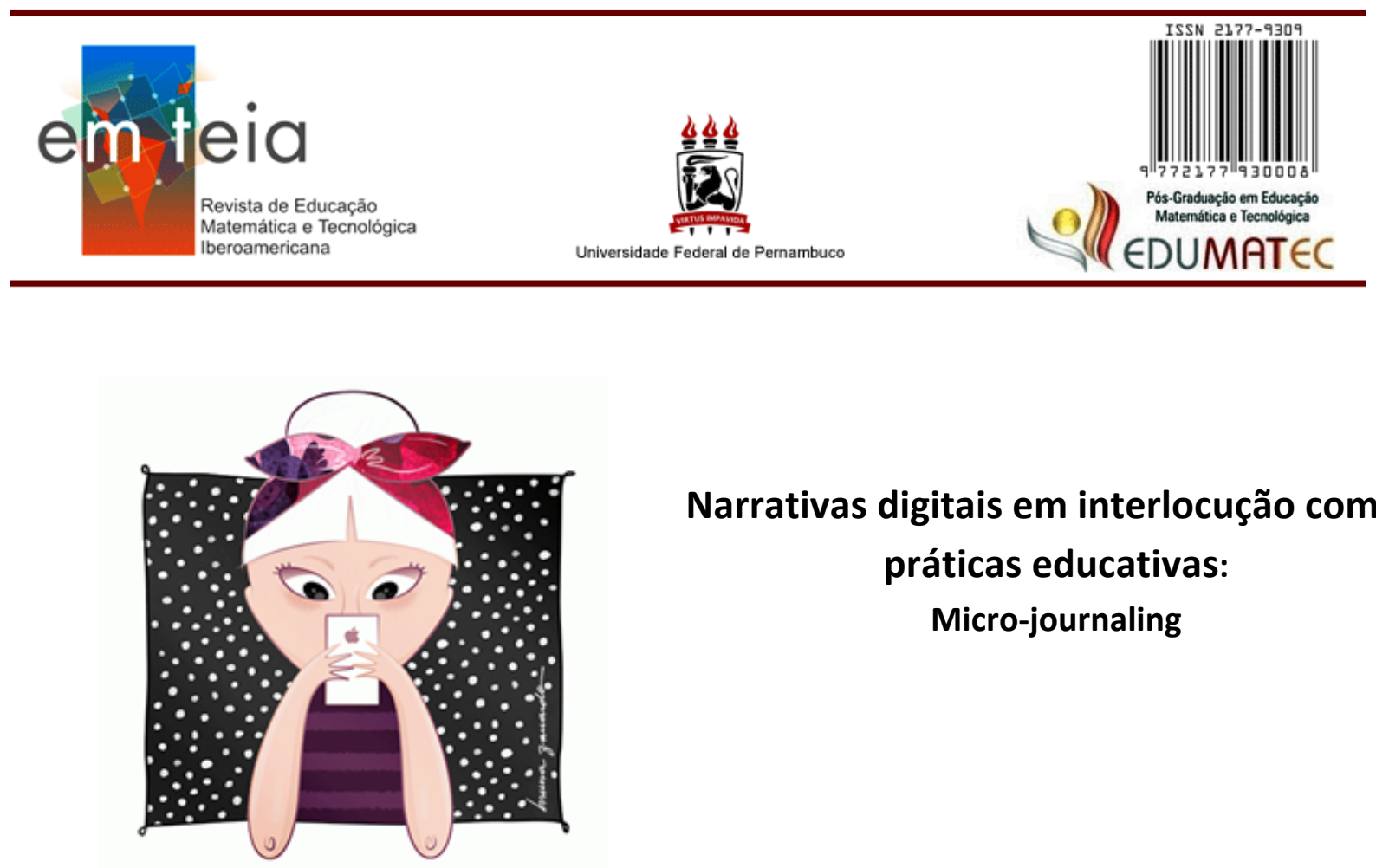

\title{
Narrativas digitais em interlocução com as práticas educativas: \\ Micro-journaling
}

Rosangela Silveira Garcia ${ }^{1}$

prof.rosegarcia@gmail.com

Adriana Rocha Bruno ${ }^{2}$

adriana.bruno@educacao.ufjf.br

Ygor Correa ${ }^{3}$

correaygorprof@gmail.com

\footnotetext{
${ }^{1}$ Doutora em Informática na Educação (UFRGS). Mestre em Linguística Aplicada. Pós-Graduada em Gestão Escolar. Licenciada em Letras e Licencianda em Pedagogia. Pesquisadora do LELIC/UFRGS (Laboratório de estudos em linguagens, interação e cognição). http://lattes.cnpq.br/9703728489958669

2 Pós doutora em Educação pelo Instituto de Educação da Universidade de Lisboa-PT, Doutora e Mestre em Educação: Currículo pela Pontifícia Universidade Católica de São Paulo e licenciada em Pedagogia. É professora Associada do Depto. de Educação, da Universidade Federal de Juiz de Fora (UFJF), professora dos Programas de Pós-Graduação em Educação e em Gestão e Avaliação da Educação Pública - ambos da UFJF. É líder do Grupo de Pesquisa Aprendizagem em Rede - GRUPAR. Coordenadora do Curso de Especialização Mídias na Educação da UFJF. Site: https://sites.google.com/site/arbruno Lattes: http://lattes.cnpq.br/9966072704077985 Facebook: Adriana Rocha Bruno

${ }^{3}$ Pós-Doutorando no Centro Universitário Ritter dos Reis (UniRitter) na linha de pesquisa em Design, Tecnologia e Educação. Doutor em Informática na Educação pela Universidade Federal do Rio Grande do Sul (UFRGS PPGIE). Mestre em Linguística Aplicada - Universidade do Vale do Rio do Sinos (UNISINOS - PPGLA). Graduação em Letras-Inglês pela UNISINOS.
} 


\section{Introdução}

O presente artigo tem como foco a integração de narrativas digitais nas práticas educativas por meio de propostas inovadoras, como a do micro-journaling. Para tanto, os autores trazem como objetivos: compreender o cenário educacional atual da sociedade em rede e as premissas para uma Cultura de Convergência; identificar as potencialidades do uso de recursos digitais na sua prática pedagógica para qualificação do processo de ensino e aprendizagem e de atividades interdisciplinares; favorecer a inclusão digital e o processo de autoria nas práticas pedagógicas e fomentar a produção de narrativas digitais por meio do processo de micro-journaling. A abordagem teórico-metodológica alicerça-se na pesquisa qualitativa narrativa pelo qual a experiência está no cerne da investigação e que tem, nas práticas, os movimentos de sua realização.

Falamos, portanto, de pesquisas que trazem elementos múltiplos da cultura.

Vivemos o que podemos chamar de multiculturalidade e, portanto, temos uma pluralidade cultural nos diversos espaços sociais em que estamos imersos. A cultura é produzida por sujeitos que, na sua relação com o outro e com o meio, se constituem sociais e históricos. Não é estática, e nem tampouco fragmentada, e se ressignifica na medida em que as relações são construídas, ao longo dos tempos, nas diversas ambiências, por meio da linguagem.

“Para o surgimento da linguagem, então, precisa-se de uma história de encontros recorrentes entre organismos que possibilite a coordenação conjunta de ações do conviver cotidiano deles" (GONZÁLES, 1993, p. 30).

Os sujeitos em interação transformam o mundo por meio da linguagem. O nosso linguajar está impregnado de sentidos que advêm de outros sentidos. Temos o sentido do sentido em nossas conversações mediadas pelo linguajar na intencionalidade de se comunicar, mas fundamentalmente de se relacionar e se transformar (BRUNO, 2002).

Gusdorf já sinalizava que a linguagem é múltipla e integradora: “a expressão manifesta o eu, a comunicação é procura do tu, tendendo o eu e o tu a unir-se na unidade do nós" (GUSDORF, 1970, p. 53). Destarte, como 'espécie fabuladora'4, é por meio das narrativas que nos relacionamos com o mundo, que aprendemos, que ensinamos, que interagimos. Nos

\footnotetext{
${ }^{4}$ Em alusão ao romance de Nancy Huston (HUSTON, Nancy. A espécie fabuladora. Porto Alegre: L\&PM, 2010).
} 
servimos de dispositivos, como já apontava Vygotsky (1999), para mediar nossa relação com o mundo, e hoje tais interfaces são digitais e em rede, compondo a cibercultura.

A cibercultura (LÉVY, 1999), compreendida como uma cultura contemporânea que traz nas tecnologias digitais sua marca, indica que, direta ou indiretamente, somos por ela influenciados e influenciamos seu desenvolvimento.

Os recursos midiáticos estão a serviço do desenvolvimento da autonomia dos sujeitos, tanto do ponto de vista da apropriação técnico-tecnológica, quanto da ampliação da criticidade e da criatividade. Estes aspectos envolvem a criação em redes de aprendizagem que não se limitam à apropriação de recursos, mas ao processo de conscientização do significado das mídias e dos meios de comunicação para a formação crítica do indivíduo, do cidadão, sujeito histórico desse processo. Integram-se mídias, ideias, relações. Convergimos; e é este um dos diferenciais das culturas hodiernas, como quer Jenkins (2006). Segundo este autor, a cultura da convergência apresenta características singulares e os fenômenos tecnológicos são reflexo desta cultura, e não o contrário. Aspectos como participação, multiplataformas, narrativa transmídia consistem em emergências dessa cultura.

A convergência de mídias no contexto educacional e nos processos de formação (docente, discente, profissional e pessoal) é compreendida, nesse cenário, como possibilidade de experiência, de aprendizagem.

\section{Contextualizando o cenário educacional e as tecnologias digitais: um diálogo necessário}

O Centro Regional de Estudos para o Desenvolvimento da Sociedade da Informação (CETIC.BR) - em publicação sobre Tecnologias da Informação e da Comunicação na Educação (TIC Educação, 2016) - aponta que é crescente o uso de TIC nas escolas brasileiras, com um aumento de $52 \%$ do uso de tecnologias móveis para fins pedagógicos. Diante deste cenário, o Cetic.br enfatiza que $85 \%$ dos professores consideram imperativa a adoção de novos métodos de ensino e práticas pedagógicas apoiadas no uso da Internet e de dispositivos digitais, que exigem práticas de formação docente.

Por sua vez, a Fundação Getúlio Vargas de São Paulo (FGV-SP, 2016) reitera a necessidade de pesquisas científicas relacionadas à presença massiva de dispositivos móveis, tablets e smartphones, considerando que tais interfaces têm desencadeado mudanças comportamentais nos cidadãos modernos. Isso porque a FGV-SP (2016) afirma que no Brasil 
o número de smartphones superou a faixa dos 151,5 milhões de dispositivos móveis e pode chegar a 236 milhões no ano de 2018. Tal cenário tem enfatizado, a todos os educadores e pesquisadores no campo da educação a necessidade de mudanças ainda mais radicais nas práticas pedagógicas. Temos acompanhado transformações significativas nas ações cotidianas dos docentes, em interação e por meio da relação com os discentes. E o foco central deste artigo mostra que temos colaborado muito para que a cultura digital se mostre também nas escolas e universidades brasileiras.

Com a chegada das tecnologias digitais às salas de aula, e com a necessidade de atender às novas gerações (TAPSCOTT, 2010; VEEN; VRAKKING, 2009; PRENSKY, 2001), advém a necessidade de os professores integrarem, cada vez mais, recursos tecnológicos digitais às suas práticas para qualificar o processo de ensino e aprendizagem. Silva (2010), com a proposta de sala de aula interativa, sugere, entre outros aspectos, o uso de material didático digital no qual o estudante tem acesso aos conteúdos de forma interativa, ou seja, que permite ao estudante interagir com os conteúdos e assim aprender em interação com o meio.

De fato, a era tecnológica e sua correlação com a educação é pauta de debate nos mais distintos setores da sociedade (universidades, organizações não governamentais, meios de comunicação etc.). A escola é introduzida nessa discussão quando se colocam em crise os modelos clássicos e tradicionais de ensinar e aprender frente às novas possibilidades oferecidas pelos recursos tecnológicos. Para Moran, os processos de ensinar e de aprender

estão sendo desafiados como nunca antes. Há informações demais, múltiplas fontes, visões diferentes de mundo. Educar hoje é mais complexo porque a sociedade também é mais complexa e também o são as competências necessárias. É de suma importância repensar o ensino e a inserção efetiva da tecnologia no processo educativo, em especial considerando a escola como espaço privilegiado para a formação crítica (2000, p. 245-253).

O mundo contemporâneo estabelece ao mesmo tempo um desafio e uma oportunidade ao mundo da educação. É necessário, entretanto, que a discussão sobre o uso de tecnologias no processo educativo parta do pressuposto de que as TIC, sozinhas, não se estabelecem como solução para os problemas da educação, nem que a mudança educacional será conduzida pelas novas tecnologias da informação e da comunicação. Acesso à informação não é garantia de produção de conhecimento e, muito menos, aprendizagem. A educação de qualidade não será construída por meio de ferramentas de última geração, internet de alta 
velocidade ou ambientes virtuais de aprendizagem, mas através dos atores sociais que participam de sua edificação.

A educação tem que surpreender, cativar, conquistar os estudantes a todo momento. A educação precisa encantar, entusiasmar, seduzir, apontar possibilidades e realizar novos conhecimentos e práticas. O conhecimento se constrói a partir de constantes desafios, de atividades significativas, que excitem a curiosidade, a imaginação e a criatividade (MORAN, 2007, p. 167169).

Neste sentido, apresenta-se a prática pedagógica de produção de narrativas digitais através de aplicativos que fomentam o processo conhecido como micro-journaling. Consideramos que tal prática estimula o processo criativo, incentiva a autoria e, como recurso educacional, favorece a integração de atividades interdisciplinares e a inclusão digital de alunos e educadores.

\section{Narrativas digitais como processos de enunciação}

Conceituar narrativa não se configura como tarefa fácil; o termo tem sido utilizado pelas mais distintas áreas e com diferentes objetivos.

Garcia (2017), em pesquisa realizada sobre esta temática em dissertações e teses junto ao Banco de Teses Capes defendidas no período de 2010 a 2014, revela que percentual significativo destes estudos teve como princípio metodológico orientador a investigação da identidade profissional e práxis docente, e investigação da construção composicional do narrar como gênero textual. Frisa também que em nenhuma das pesquisas observou-se como cenário de produção o espaço online.

Partindo de uma perspectiva bakhtiniana, entendemos o sujeito social que está no mundo digital - que fala sobre si, sobre o outro e sobre o mundo no contexto online - como sujeito de enunciação, que se constitui a partir da interação social com outros nos múltiplos espaços digitais que habita.

Garcia (2017) discute o narrar no contexto digital e a necessidade de estudos sobre suas especificidades. A autora destaca a necessidade de assunção de uma postura teórica bem delineada sobre o que se compreende como narrar, seja a abordagem situada ou não no campo linguístico. 
Aqui, assumiremos uma concepção de narrar como processo enunciativo (BAKHTIN, 2002, 2003, 2008); pela especificidade do micro-journaling: autobiográfico (PASSEGGI, 2008; SOUZA, 2004; BAKHTIN, 2003, 2012); pelo seu caráter: como prática social (BRUNER, 1990, 1991, 2002; BAMBERG, 1996; BROCKMEIER; HARRÉ, 2003).

$\mathrm{Na}$ abordagem conceitual sobre o narrar como processo enunciativo, na perspectiva bakhtiniana, dois pontos são necessários explorar: enunciado e processo de enunciação. Para o filósofo da linguagem, a enunciação se estabelece como um diálogo produzido por meio da interação de sujeitos sociais, ou seja, o processo de enunciação decorre do agir pela linguagem dos sujeitos e das suas relações sociais, históricas e contextuais com o meio em que estão inseridos. A enunciação se concretiza no discurso por meio de enunciados, como atividade de linguagem produzida por meio de relações dialógicas. O enunciado, produto da enunciação, constitui o discurso sendo um ato individual que pressupõe um sujeito, ele possui conexão responsiva com outros enunciados que o antecedem e/ou procedem, é a materialização das práticas comunicativas do sujeito (BAKHTIN, 2002, 2003, 2008).

Ressaltamos que o cenário do narrar ao qual nossa discussão se dirige - o espaço digital - tem, aparentemente, como meta estimular o narrar sobre si mesmo, incentivado pela própria interface dos aplicativos usados na prática de micro-journaling que observamos. Dessa forma, fomos buscar em Passeggi (2008), Bakhtin (2003, 2012) e Souza (2004) subsídios para entender as especificidades da autobiografia nos modos de narrar.

Passeggi (2008) compreende a autobiografia como o eu consciente de si mesmo, que arquiteta a tessitura de uma figura pública de si, sendo o narrar autobiográfico instituído de marcas individuais e coletivas que emergem das memórias - enquanto construção social - de experiências e lembranças. Bakhtin $(2003,2012)$ situa o autobiográfico como base organizadora da narrativa - constitutivo de existência do sujeito que narra - que fornece forma à consciência, à perspectiva de minha própria vida e ao discurso assumido. Para Souza (2004, p. 72), narrar sobre si envolve "auto-escuta de si mesmo, como se estivesse contando para si próprio suas experiências e aprendizagens que construiu ao longo da vida, através do conhecimento de si".

Assim como a linguagem é um ato e fato social, o narrar - composição específica enunciativa - também o é. Para Bruner (1990, 1991, 2002) e Bamberg (1996), a narrativa é uma prática social organizadora de versões da realidade, diretamente relacionada ao discurso 
comunicativo, em que a aceitação de veracidade é regida por convenções estabelecidas entre os sujeitos e media a experiência e configura a construção social da realidade. Para Bamberg (1996), toda narrativa é, simultaneamente, um ato de (re)construção, no qual a realidade social se produz na relação com o mundo social por meio de uma autodescrição - perspectiva singular do sujeito.

Brockmeier e Harré (2003) defendem que não existe narrativa, mas narrativas (conjunto de estruturas linguísticas e psicológicas transmitidas cultural e historicamente) construídas a partir de determinados pontos de vista delineados pelo contexto e pelas vozes que nele se apresentam. Esses autores afirmam que as narrativas seriam um modo específico de construção e constituição da realidade que compõe um conjunto de regras do que é aceito, ou não, em determinada cultura.

\title{
Micro-journaling: conceito e aplicabilidade educacional
}

\begin{abstract}
\#SAIBA MAIS\#
Em 2008, o jornal The New York Times14 publicou artigos escritos pelo seu colunista Noam Cohen, no qual utiliza a expressão microjornalismo (microjournalism em inglês) para se referir à cobertura das prévias das eleições norte-americanas, através do Twitter. O primeiro, publicado em janeiro de 2008, chamava a atenção pelo título "Relatório de campanhas em 140 toques". O artigo explana sobre os bastidores das prévias divulgados através do Twitter, minuto a minuto, pelo corresponde político e chefe da revista online Slate, John Dickerson e que fez o microjornalismo surgir. 0 texto ainda afirma que o microjornalismo é o último passo na evolução do senhor Dickerson, que trabalhou durante anos na revista Time, e passou do impresso para artigos online, aos blogs e para mensagens de texto que não ultrapassam 140 caracteres ou cerca de duas frases (BITAR; ROCHA, 2016).
\end{abstract}

$\mathrm{Na}$ atualidade, o micro-journaling, não restrito mais a profissionais do jornalismo, se constitui na micro-história como definido Ginzburg (2007) - história narrada em escala reduzida - isenta de regras prescritivas no que tange a subjetividade do narrador. É um olhar recortado, distinto e aprofundado de determinado contexto explorado. O Twitter, citado no exemplo acima, é um bom exemplo da prática de micro-journaling.

\section{\#CONECTANDO\#}

A experiência do narrar (Micro-journaling) de Ariel Bissett comprova que o narrar sobre si pode emergir de distintos formatos. Acesse o link e conecte-se a experiência. 
\#CONECTANDO\#

https://youtu.be/izAl_20vlyM - A experiência do narrar (Micro-journaling) de Ariel Bissett

Assim como o exemplo de Ariel Bisset, o narrar sobre si no contexto digital virou uma forma de publicização do cotidiano. Além do Twitter, outros recursos têm explorado esta forma de enunciação, podemos citar entre eles: o Instagram (rede social online de compartilhamento de fotos e vídeos entre seus usuários); a rede social Facebook; o Youtube (rede de compartilhamento de vídeos); o Whatsapp (aplicativo para smartphones que permite mensagens instantâneas, chamadas de vídeo e compartilhamento de status). Acesse os links na nota de rodapé e navegue pelo infográfico sobre as redes sociais mais acessadas no mundo.

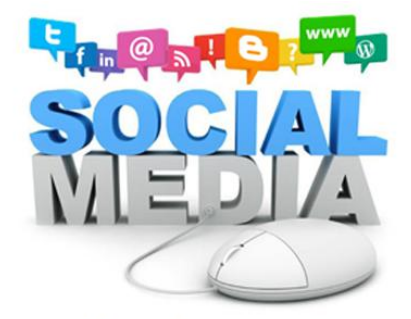

\section{E nas escolas, como podemos integrar recursos tecnológicos na produção de narrativas digitais?}

Pensar a integração de recursos digitais no cotidiano escolar - que rompam barreiras físicas (da sala de aula) e temporais (horário pré-determinado das disciplinas) - em que o

\footnotetext{
${ }^{5}$ http://www.techtudo.com.br/dicas-e-tutoriais/noticia/2014/01/conheca-o-timehop-maquina-do-tempo-dasredes-sociais-para-ios.html - timehop

https://play.google.com/store/apps/details?id=net.nakvic.dromoris - memories

https://play.google.com/store/apps/details?id=com.pixelcrater.Diaro Diário

https://play.google.com/store/apps/details?id=com.rz.personal.diary - meu diário pessoal
} 
ensino ocupe novos territórios, exige do educador a construção de uma proposta de ensino onde ele não é o principal ator.

A escolha pelo uso de celulares smartphones como recurso pedagógico, utilizado no projeto aplicado pela primeira autora deste artigo, se justifica por dois aspectos importantes do contexto tecnológico brasileiro.

Em primeiro lugar, é fato que as escolas, principalmente as públicas, não possuem em sua maioria - estrutura para uso de recursos tecnológicos. Observamos diariamente notícias sobre deficiências encontradas em laboratórios de informática nas escolas: baixa, ou nenhuma, conexão com a internet; equipamentos em constante manutenção e em número insuficiente para uso dos alunos. E que, na contramão desta tendência de sucateamento dos laboratórios de informática nas escolas, cresce o uso de celulares por professores e alunos, como evidencia o gráfico abaixo.

\section{GRÁFICO 01 - PRINCIPAIS EQUIPAMENTOS USADOS POR ALUNOS PARA ACESSAR A INTERNET}

Porcentagem sobre o total de estudantes participantes da pesquisa CETIC

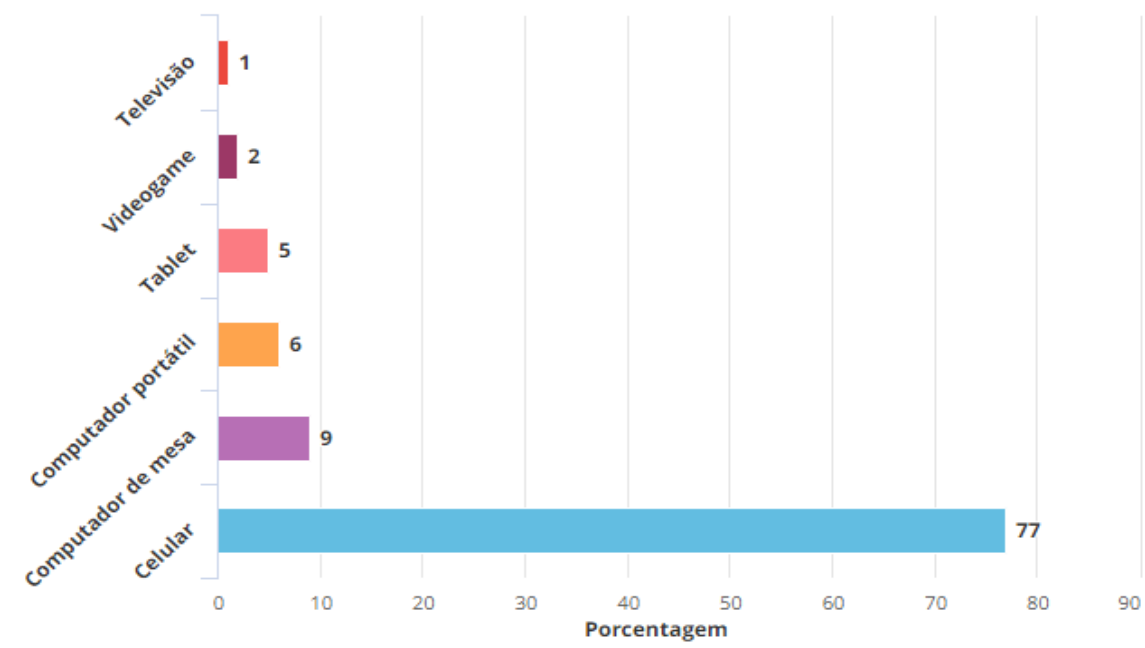

Fonte: CGI.br/NIC.br/Cetic.br/TIC Educação 2016

Dados da Cetic (Centro de Estudos sobre as Tecnologias da Informação e da Comunicação) apontam também que 52\% das instituições de educação básica usam celular em atividades escolares e que, em 2016, 91\% dos professores possuíam smartphone e $61 \%$ usavam essa tecnologia nas suas práticas. 
O segundo ponto importante se refere à própria evolução dos aparelhos celulares (Figura 01), que emergem como possibilidade de suprir a carência na estrutura tecnológica das escolas.

FIGURA 01 - EVOLUÇÃO DOS SMARTPHONES NO BRASIL

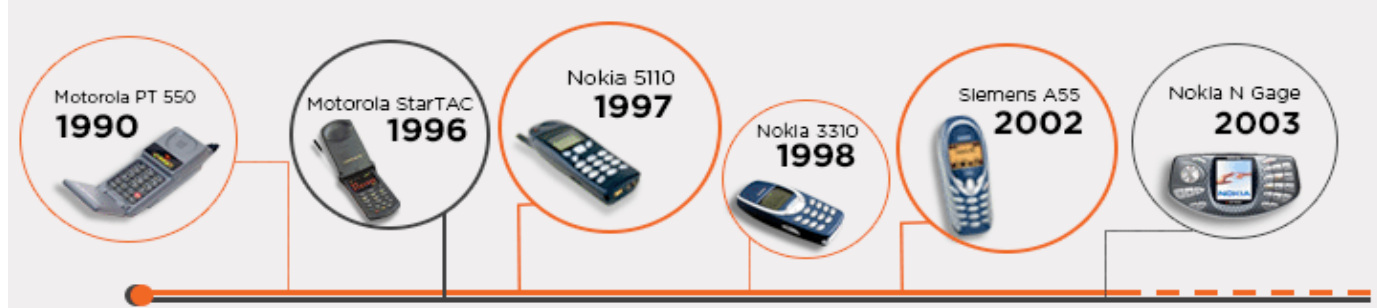

A EVOLUÇÃO DOS SMARTPHONES NO BRASIL

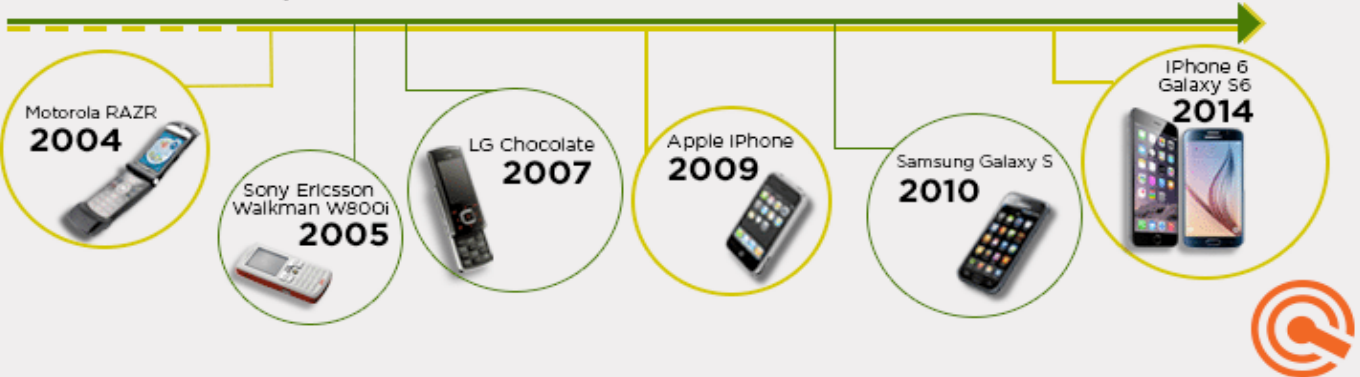

Fonte: ALVES, David. Brasil: uma história contada por celulares. Disponível em: https://www.showmetech.com.br/brasil-uma-historia-contada-por-celulares/. Acesso em: 20 mar. 2018.

Aparelhos celulares, na atualidade, deixaram de lado a simples função de um telefone e convertem-se em equipamento - pessoal, portátil, interativo - que possibilita intensa imersão no mundo digital. Você pode com um simples touch acessar suas redes sociais, enviar mensagens e vídeos, conversar em tempo real com pessoas distantes geograficamente, navegar na internet e, sim, ainda fazer uma ligação.

\section{\#CONECTANDO\#}

A Organização das Nações Unidas para Educação, a Ciência e Cultura (UNESCO) tem como uma de suas metas incentivar governos a promoverem a educação móvel, utilizando aparelhos celulares como recurso pedagógico.

Para mais informações sobre a Semana de Aprendizagem Móvel 2018: Preparando-se para atender aos requisitos de habilidades de um mundo conectado, no site do Mobile Learning Week - https://en.unesco.org/m/w/2018 
Consoante este contexto, a proposta que trazemos, já aplicada em turmas de graduação, em disciplina totalmente a distância, é a de uso de aplicativos - softwares utilizados em celulares - como espaço de produção de conhecimento, de autoria e de prática interdisciplinar, por meio da construção de narrativas digitais.

As etapas do projeto "Narrar Digital" se organizaram da seguinte forma:

1. Criação de Fórum de Discussão no AVA (Ambiente Virtual de Aprendizagem) Moodle. Como contextualização, utilizou-se excerto do filme Escritores da Liberdade. A proposta de discussão se voltou às especificidades do narrar autobiográfico em diários e à atualização desta prática no contexto contemporâneo.

2. Posterior à discussão, uma atividade de micro-journaling foi proposta. Nesta atividade o aluno deveria utilizar o aplicativo Timehop ${ }^{6}$ - aplicativo que reúne posts antigos extraídos do histórico de redes sociais do usuário -, recolher estes dados durante uma semana e registrar suas impressões sobre as postagens.

3. Finalizada a coleta das postagens, os alunos deveriam realizar a produção de uma narrativa autobiográfica, com a condição de que as postagens seriam pano de fundo para a produção de uma nova narrativa, integrando as postagens e suas impressões sobre ela. Esta atividade, a pedido dos alunos, foi realizada em outro aplicativo sugerido por eles - Memoires: the Diary - e compartilhada na pasta do Google Drive da turma.

Ressaltamos ao docente a compreensão do desafio de estar frente a mudanças na prática pedagógica, e alguns fatores devem ser apresentados: a resistência ao desenvolvimento de um projeto que altere a prática defendida pelo currículo escolar; a falta de recursos materiais; a resistência inicial dos alunos frente a uma abordagem metodológica que exige que assumam a responsabilidade como agentes ativos de sua aprendizagem.

Durante o desenvolvimento da atividade de produção do micro-journaling estes fatores se fizeram presentes, entretanto, um engajamento maior dos alunos ocorreu na fase de produção da atividade. O momento mais perceptível da mudança foi frente à observação dos dados levantados pelo Timehop das postagens em uma linha de tempo cronológica. Posterior, outro momento significante, segundo os alunos, foi a liberdade de autoria.

\footnotetext{
${ }^{6} \mathrm{https}: / /$ timehop.com/
} 
Consideramos que tal prática estimulou o processo criativo dos alunos e o exercício da autoria, bem como um olhar mais crítico para as formas como enunciam em sites de redes sociais e de como estamos imersos de forma profunda no contexto online.

As palavras de Oliveira (2003, p. 134) refletem nossa perspectiva quando afirma que

\begin{abstract}
Dentro e fora da sala de aula - que não precisa ser exorcizada, mas expandida e atualizada - o estudante deve atuar diretamente sobre a formação de seus saberes e competências, os quais permanecem em constante e dinâmica renovação. Para isso, deve ter acesso e precisa ser incentivado à apropriação da tecnologia disponível, sem que, com isso, o professor perca de vista sua estratégia didático-pedagógica. O professor, como elemento essencial que é, aprendendo a lidar com o instrumental tecnológico a serviço da educação, tende a renovar sua prática e adequá-la às reconfigurações urgentes que se fazem necessárias na escola.
\end{abstract}

Um fator primordial na implantação de recursos tecnológicos em apoio ao aprendizado na escola deve ser delinear os pressupostos teóricos que justificam a mudança de prática, planificando o projeto, destacando o que se quer fazer, descrevendo os objetivos do planejamento para, futuramente, comparar com os resultados alcançados.

É insuficiente somente alocar recursos tecnológicos no ambiente escolar. A tecnologia isolada não promove a aprendizagem significativa e produção de conhecimento, e por isso deve existir formação contextualizada dos docentes que atuam neste espaço para enfrentar os desafios de uso de dispositivos digitais e em rede como recursos de apoio à aprendizagem. De acordo com Faria (2004), a diferença didática não está na utilização (ou não) de recursos tecnológicos, mas no conhecimento de suas possibilidades e limitações. O diferencial consistirá na forma como professores e estudantes, parceiros de trabalho, farão uso de tais recursos tecnológicos, explorando seu potencial para a produção de novos projetos educacionais.

\title{
\#SAIBA MAIS\#
}

Apresentaremos quatro aplicativos para celulares com sistema Android que podem ser utilizados para produção de micro-journaling. 


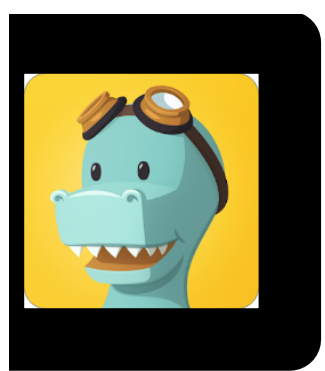

Timehop

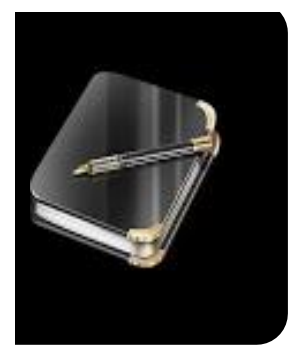

Memoires: the Diary

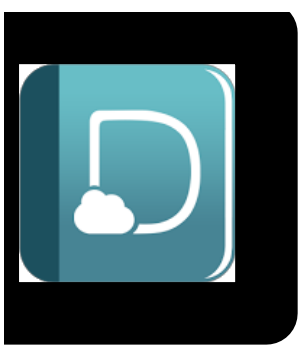

Diaro - diary, journal, notes

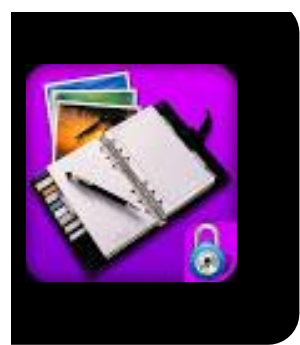

Meu Diário Pessoal

\section{\#SAIBA MAIS\#}

\section{Novos olhares a algumas reflexões}

Os dispositivos digitais e em rede estão a serviço de uma educação que enxergue o sujeito como ator parceiro do processo de construção de uma sociedade mais justa e democrática. $\mathrm{O}$ processo de gerar e gerir narrativas digitais assinala aspectos essenciais para a formação, tais como: a valorização das diferentes experiências para a construção da identidade do sujeito; a força e o diferencial das relações intersubjetivas para a apropriação e transformação da linguagem em consonância com a cultura da convergência e da cibercultura; o espaço e o tempo para o diálogo; a mediação simbólica construtiva para propiciar trocas efetivas e reflexões complexas nas práticas educativas; a produção de desafios constantes para que o estímulo e o desejo de mudança e de criação se desenvolvam em meio à cultura digital; a presença e o compromisso de todos os envolvidos neste processo e principalmente o resgate da alteridade como movimento que transforma as relações e redimensiona as ações humanas em relação ao outro, a si mesmo e ao espaço (ambiente) vivido e vivente.

O desenvolvimento de novas metodologias de ensino e de aprendizagem deve criar ambientes que sejam envolventes, de forma a propiciar uma aprendizagem capaz de pôr em movimento estratégias e habilidades do pensamento crítico.

\section{Referências}

BAKHTIN, M. Questões de Literatura e de Estética. São Paulo: Hucitec, 2002. . Estética da criação verbal. Trad. Paulo Bezerra. 4. ed. São Paulo: Martins Fontes, 2003. 
Problemas da poética de Dostoiévski. 4. ed. Rio de Janeiro: Forense Universitária, 2008.

. Para uma filosofia do ato. Trad. de Carlos Alberto Faraco e Cristóvão Tezza. São Paulo: Pedro \& João Editora, 2012.

BAMBERG, M. Narrative development: six approaches. Mahwah, NJ: Lawrence Erlbaum Associates, 1996.

BITAR, Marina Parreira Barros; ROCHA, Liana Vidigal. Microjornalismo no Twitter: aspectos da estrutura jornalística na rede social. TEMATICA. Ano XII, n. 01. Abril/2016. NAMID/UFPB Disponível em http://periodicos.ufpb.br/ojs2/index.php/tematica. Acesso em: 31 jan. 2018.

BROCKMEIER, Jens; HARRÉ, Rom. Narrativa: problemas e promessas de um paradigma alternativo. Psicologia: Reflexão e Crítica, Porto Alegre, v. 16, n. 3, p. 525-535, 2003.

BRUNER, J. Acts of Meaning. Cambridge, MA: Harvard University Press, 1990.

Actual minds, possible worlds. Cambridge, MA: Harvard University Press, 1991.

Making stories: law, literature, life. Cambridge, MA: Harvard University Press, 2002.

BRUNO, A. R. A Linguagem Emocional em Ambientes Telemáticos: tecendo a razão e a emoção na formação de educadores. 2002. Dissertação (Mestrado) - PUC, São Paulo, 2002.

CENTRO REGIONAL de Estudos para o Desenvolvimento da Sociedade da Informação (Cetic.br). TIC Educação 2016. Disponível em: http://cetic.br/pesquisa/educacao/. Acesso em: 18 mar. 2018.

FARIA, Elaine Turk. O Professor e as Novas Tecnologias. In: ENRICONE, Délcia. Ser Professor. 4. ed. Porto Alegre: EDIPUCRS, 2004.

GARCIA, R. S. Entre abas: processos de enunciação em rede. 2017, 184f. Tese (Doutorado) Programa de Pós-Graduação em Informática na Educação, Universidade Federal do Rio Grande do Sul, Porto Alegre, 2017.

GINZBURG, C. O fio e os rastros. Verdadeiro, falso, fictício. Tradução de: Rosa Freire d'Aguiar e Eduardo Brandão. São Paulo: Companhia das Letras, 2007.

GONZÁLES, J. E. M. Emoção como fundamento das interações humanas: um estudo a partir das obras de Humberto Maturana. 1993. Dissertação (Mestrado em Psicologia da Educação) - Pontifícia Universidade Católica de São Paulo/PUCSP, São Paulo, 1993. 
GUSDORF, G. A Fala. Lisboa/PT: Colecção Humanitas - ISCSPU, 1970.

JENKINS, H. Convergence culture: where old an new media collide. Nova York: New York University Press, 2006.

LÉVY, P. Cibercultura. São Paulo: Ed. 34, 1999.

MORAN, José Manuel. Ensino e Aprendizagem Inovadores com Tecnologias Audiovisuais e Telemáticas. In: et al. Novas Tecnologias e Mediação Pedagógicas. Campinas, SP: Papirus, 2000. Coleção Papirus Educação.

A educação que desejamos: Novos desafios e como chegar lá. Campinas: Papirus, 2007, p.167-169. Disponível em: http://www.eca.usp.br/prof/moran/desejamos.htm

PASSEGGI, Maria da Conceição. Memoriais: injunção institucional e sedução autobiográfica. In: PASSEGGI, Maria da Conceição; SOUZA, Clementino de (Org.). (Auto)Biografia: formação, territórios e saberes. São Paulo: PAULUS; Natal: EDUFRN, p. 103-132, 2008.

PRENSKY, M. Digital Native, digital immmigrants. Digital Native immigrants. On the horizon, MCB University Press, v. 9, n. 5, October 2001. Acesso em: 07 set. 2012.

OLIVEIRA, Gerson P. Uma experiência de avaliação formativa à distância apoiada por computador no ensino superior: da sala de aula para o mundo. Anais do XI Encontro Nacional de Didática e Práticas de Ensino. Goiânia, 2003.

SILVA, M. Sala de aula interativa: educação, comunicação, mídia clássica, internet, tecnologias digitais, arte, mercado, sociedade, cidadania. 5. ed. São Paulo: Loyola, 2010.

SOUZA, Eliseu Clementino. O conhecimento de si: Narrativas do itinerário escolar e formação de professores. 2004, 442f. Tese (Doutorado em Educação) - Faculdade de Educação, Universidade Federal da Bahia, Terra, 2004.

TAPSCOTT, D. A hora da geração digital: como os jovens que cresceram usando a internet estão mudando tudo, das empresas aos governos. Rio de Janeiro: Agir Negócios, 2010.

VEEN, W.; VRAKKING, B. Homo Zappiens: educando na era digital. Trad. de Vinícius Figueira. Porto Alegre: Artmed, 2009.

VYGOTSKY, L. S. Pensamento e linguagem. São Paulo: Martins Fontes, 1999. 